\title{
Telomerase prevents accelerated senescence in glucose-6-phosphate dehydrogenase (G6PD)-deficient human fibroblasts
}

\author{
Yi-Hsuan $\mathrm{Wu}^{1}$, Mei-Ling Cheng2, Hung-Yao $\mathrm{Ho}^{2}$, Daniel Tsun-Yee Chiu*2 \\ and Tzu-Chien V Wang*3
}

Address: ${ }^{1}$ Graduate Institute of Basic Medical Sciences, Chang Gung University, Kwei-San, Tao-Yuan 333, Taiwan, ${ }^{2}$ School of Medical Biotechnology, Chang Gung University, Kwei-San, Tao-Yuan 333, Taiwan and ${ }^{3}$ Department of Molecular and Cellular Biology, Chang Gung University, Kwei-San, Tao-Yuan 333, Taiwan

Email: Yi-Hsuan Wu -d9101302@stmail.cgu.edu.tw; Mei-Ling Cheng - chengm@mail.cgu.edu.tw; Hung-Yao Ho - hoh01@mail.cgu.edu.tw; Daniel Tsun-Yee Chiu* - dtychiu@mail.cgu.edu.tw; Tzu-Chien V Wang* - tcrwg@ mail.cgu.edu.tw

* Corresponding authors

Published: 5 February 2009

Journal of Biomedical Science 2009, 16:18 doi:10.1186/1423-0127-16-18

This article is available from: http://www.jbiomedsci.com/content/16/1/18

(c) 2009 Wu et al; licensee BioMed Central Ltd.

This is an Open Access article distributed under the terms of the Creative Commons Attribution License (http://creativecommons.org/licenses/by/2.0), which permits unrestricted use, distribution, and reproduction in any medium, provided the original work is properly cited.
Received: 29 October 2008

Accepted: 5 February 2009

\begin{abstract}
Fibroblasts derived from glucose-6-phosphate dehydrogenase (G6PD)-deficient patients display retarded growth and accelerated cellular senescence that is attributable to increased accumulation of oxidative DNA damage and increased sensitivity to oxidant-induced senescence, but not to accelerated telomere attrition. Here, we show that ectopic expression of hTERT stimulates telomerase activity and prevents accelerated senescence in G6PD-deficient cells. Stable clones derived from hTERT-expressing normal and G6PD-deficient fibroblasts have normal karyotypes, and display no sign of senescence beyond 145 and 105 passages, respectively. Activation of telomerase, however, does not prevent telomere attrition in earlier-passage cells, but does stabilize telomere lengths at later passages. In addition, we provide evidence that ectopic expression of hTERT attenuates the increased sensitivity of G6PD-deficient fibroblasts to oxidant-induced senescence. These results suggest that ectopic expression of hTERT, in addition to acting in telomere length maintenance by activating telomerase, also functions in regulating senescence induction.
\end{abstract}

\section{Background}

Normal human cells grown in vitro replicate for a limited period of time before entering senescence [1], a term that has been used primarily to describe a signal transduction pathway that leads to the irreversible growth arrest of cells in culture. Among the various stimuli that are known to trigger senescence $[2,3]$, telomere attrition and oxidative damage (produced during normal cellular proliferation) are the basis for the "telomere hypothesis" $[4,5]$ and "free radical theory" $[6,7]$, respectively, postulated to account for the aging process.

According to the "telomere hypothesis" of aging, dysfunctional telomeres caused by telomere attrition are postulated to initiate the senescent phenotypes. Telomere attrition occurs because the ends of linear chromosomal DNA cannot be completely replicated by normal DNA polymerases, and, therefore, telomere DNA becomes 
shortened with each round of DNA replication $[8,9]$. When telomeres reach a critical length, they become dysfunctional and trigger so-called replicative senescence. Activation of telomere length-maintenance mechanisms, such as expression of telomerase, a specialized reverse transcriptase that synthesizes telomeric DNA repeats at chromosome ends, is thought to counteract replicative senescence $[5,10,11]$. In support of this postulate, normal human somatic cells express low or undetectable telomerase activity and are mortal. In contrast, a majority of immortal and cancer cells have an indefinite proliferative capacity and maintain their telomere length by upregulating telomerase $[12,13]$. Ectopic expression of telomerase has been shown to extend the lifespan of many normal human cells cultured in vitro [14-16].

The free radical theory of aging postulates that the accumulation of oxidative damage is the central mediator of the aging process [6,7]. Reactive oxygen species produced during normal cellular metabolism or from exogenous sources, such as drugs and radiation, are known to react with biomolecules, including proteins and DNA. It is this accumulation of oxidative damage over time that is postulated to trigger senescence [6]. In support of this hypothesis, exposure to oxidative stress (e.g., tert-butyl hydroperoxide, hydrogen peroxide, or a hyperbaric atmosphere with high $\mathrm{O}_{2}$ partial pressure) triggers senescence, and oxidative DNA damage is known to accrue during senescence [17-23]. In addition, growth of cells under hypoxic conditions $\left(3 \%[\mathrm{v} / \mathrm{v}] \mathrm{O}_{2}\right.$ instead of the normal atmospheric $\mathrm{O}_{2}$ level) is known to delay cellular senescence of fibroblasts [24].

Despite supporting evidence for both of these theories, based on multiple experimental approaches, little is known about the relative roles of these two mechanisms in the induction of senescence or the potential interactions of the signaling pathways they trigger. Recently, we have shown that fibroblasts derived from glucose-6-phosphate dehydrogenase (G6PD)-deficient patients displayed retarded growth and accelerated cellular senescence [25]. Evidence indicates that the accelerated cellular senescence observed in G6PD-deficient cells arises because of increased accumulation of oxidative DNA damage and an increased sensitivity to oxidant-induced senescence, but not to accelerated telomere attrition [26]. These data indicate that G6PD status - and thus proper redox balance - is a determinant of cellular senescence. It is not yet known, however, whether increased oxidative DNA damage is the only important determinant of senescence induction in G6PD-deficient cells. To address this point, we asked whether activation of telomerase activity might be capable of overcoming the accelerated senescence observed in such cells. Here, we present evidence that ectopic expression of hTERT, the key regulator of tel- omerase, activates telomerase activity and prevents premature senescence in G6PD-deficient cells.

\section{Materials and methods Chemicals, enzymes and oligonucleotides}

Dulbecco's modified Eagle's medium (DMEM), trypsin, penicillin, streptomycin and amphotericin were purchased from Gibco (Karlsruhe, Germany). The anti-G6PD antibody was from Genesis Biotech (Taiwan). The antiactin antibody was from Santa Cruz Biotechnologies (Santa Cruz, CA, USA). The antibiotic, G418 sulfate, was from Promega (Madison, WI, USA). The TeloTAGGG assay kit, alkaline phosphatase and protein kinase $\mathrm{K}$ were from Roche (Roche, Mannheim, Germany). Taq DNA polymerase was from Qiagen. The sequence and source of TS and CX oligonucleotides have been described [27].

\section{Cell culture}

Normal human fibroblasts (HFF3) and G6PD-deficient fibroblasts (HFF1) were routinely cultured in DMEM supplemented with $10 \%$ fetal bovine serum, 100 units $/ \mathrm{ml}$ penicillin, 100 units $/ \mathrm{ml}$ streptomycin and $0.25 \mathrm{mg} / \mathrm{ml}$ amphotericin at $37^{\circ} \mathrm{C}$ in a humidified atmosphere containing $5 \% \mathrm{CO}_{2}$. Human fibrosarcoma cells (HT1080), used as a positive control in soft agar and telomerase assays, were from American Type Culture Collection (ATCC). BOSC23 and PT67 cells were used for preparation of retroviral particles as previously described [26].

\section{Plasmids, retroviral packaging and infection}

The plasmid, pBABE-Puro-hTERT [28], a retroviral construct that expresses hTERT, was kindly provided by Dr. E. Blackburn. Retroviral packaging and infection were accomplished as previously described [26], with the exception that the retrovirus producer cells and hTERTexpressing clones were selected in a medium containing 2 $\mu \mathrm{g} / \mathrm{ml}$ puromycin.

\section{Telomerase activity assay}

A PCR-based telomeric amplification protocol (TRAP) was used to assay telomerase activity. The preparation of cell extracts, the PCR amplification conditions, and the analysis of PCR products by electrophoresis on polyacrylamide gel were as described [29].

\section{Soft agar assay}

To assay for contact-independent growth in soft agar, cells were trypsinized and resuspended at $3.3 \times 10^{3} \mathrm{cells} / \mathrm{ml}$ in supplemented DMEM containing $0.35 \%$ melted agarose. Aliquots $(1.5 \mathrm{ml})$ of cell suspension were poured into 10-

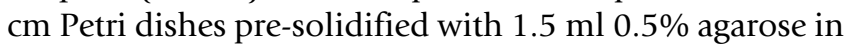
supplemented DMEM. The immobilized cells were grown for 14 days in a humidified chamber at $37^{\circ} \mathrm{C}$ with $5 \%$ $\mathrm{CO}_{2}$. Colonies were then photographed and counted. 


\section{Karyotyping of hTERT-expressing cells}

Cytogenetic examination was performed with hTERTexpressing cells at passage 11-14. After incubating with $0.06 \mu \mathrm{g} / \mathrm{ml}$ colcemid for $16 \mathrm{~h}$ to arrest cells in mitosis, fibroblasts were collected by trypsinization and fixed with Carnoy's fixative (a 3:1 mixture of methanol and glacial acetic acid). Fixed fibroblasts were placed on a glass slide, air-dried and stained with a 6\% Giemsa solution for 3.5 $\mathrm{min}$. The number of chromosomes in at least 40 cells was analyzed from each fibroblast preparation.

\section{Assay for telomere length}

Cell pellets were lysed in $1 \mathrm{M}$ Tris-EDTA buffer ( $\mathrm{pH} 7.4$ ) containing $0.5 \%$ SDS, and treated with $200 \mu \mathrm{g} / \mathrm{ml}$ proteinase $\mathrm{K}$ for $18 \mathrm{~h}$ at room temperature. Genomic DNA was then isolated by phenol-chloroform extraction. Genomic DNA was digested with HinfI and RsaI, and DNA fragments were separated by electrophoresis in $0.8 \%$ agarose gels. The DNA fragments containing telomeric repeats were identified by Southern blotting using a TeloTAGGG telomere-length assay kit (Roche, Mannheim, Germany). Average telomere fragment length (TFR) was determined from measurements of the intensity of chemiluminescent signals at each molecular mass, obtained by scanning the radiogram using a Molecular Dynamics Personal Densitometer (Sunnyvale, CA, USA). Signal densities were analyzed with ImageQuaNT software (Molecular Dynamics), and mean TRF lengths were calculated according to manufacturer's recommendation.

\section{Assay for $\mathrm{H}_{2} \mathrm{O}_{2}$-induced premature senescence}

Premature senescence was tested in fibroblasts treated with different concentrations of $\mathrm{H}_{2} \mathrm{O}_{2}$ for $1.5 \mathrm{~h}$ using senescence-associated (beta)-galactosidase (SA- $\beta$-gal) as a biomarker of senescence. After $\mathrm{H}_{2} \mathrm{O}_{2}$ treatment, the medium was replaced with fresh complete medium, and cells were cultured for $72 \mathrm{~h}$ before staining for SA- $\beta$-Gal activity as previously described [26]. Quantification of premature senescence was determined by calculating the rate of conversion of 4-methylumbellliferyl- $\beta$-D-galactopyranoside (MUG) to the fluorescent product, 4-methylumbelliferone (4-MU), at pH 6.0 as previously described [30]. The relative increase in 4-MU fluorescence per mg protein was determined by subtracting the untreated control values from the $\mathrm{H}_{2} \mathrm{O}_{2}$-treated values.

\section{Results}

Ectopic expression of hTERT immortalizes fibroblasts derived from normal and G6PD-deficient patients

To address the relative role of oxidative stress and telomere attrition in cellular senescence, we asked whether ectopic expression of hTERT might be capable of restoring telomerase activity and extending the lifespan of G6PDdeficient fibroblasts. Normal (HFF3) and G6PD-deficient fibroblasts (HFF1) were infected with the retroviral con- struct, pBABE-Puro-hTERT, which expresses hTERT under the control of the LTR promoter, and G418-resistant clones were screened for the expression of telomerase activity. G418-resistant, telomerase-positive, clones from infected normal fibroblasts (T5 and T9), or G6PD-deficient fibroblasts (GT3 and GT8), were randomly selected for further study. As shown in Figure 1, G418-resistant cells from pBABE-Puro-hTERT-transfected normal and G6PD-deficient fibroblasts expressed similarly high telomerase activity that was comparable to that of a telomerase-positive fibrosarcoma cancer cell line (HT1080), whereas no telomerase activity was detected in G418resistant cells transfected with the pBABE-Puro vector.

To determine whether ectopic expression of telomerase might be capable of extending the limited population doublings previously observed for normal and G6PDdeficient fibroblasts, we examined the proliferative capacity of hTERT-expressing fibroblasts. As shown in Fig. 2A and $2 \mathrm{~B}$, cells transfected with vector alone ceased to proliferate after about 55 and 40 passages for V1 and GV1, respectively. In contrast, hTERT-expressing fibroblasts derived from normal or G6PD-deficient patients continued to proliferate over 105 passages and showed no evidence of senescence, indicating that these cells were immortal. Accompanying the acquisition of unlimited growth potential in these fibroblasts was stable expression of telomerase activity, which persisted over the entire time of cell propagation (Fig. 2C).

\section{hTERT-immortalized G6PD-deficient fibroblasts do not exhibit a transformed phenotype}

To address the possibility that hTERT-immortalization of G6PD-deficient fibroblasts could induce changes associated with a transformed phenotype, we examined karyotype and anchorage-independent growth. Representative results of a karyotype analysis are shown for T5 and GT3 in Figure 3A. Both the hTERT-expressing normal and G6PD-deficient fibroblasts had a normal complement of diploid chromosomes (i.e., $46+\mathrm{XY}$ ), and no abnormal chromosomal structures (e.g., translocations) were detected from a total of 20 cells analyzed in each preparation. To analyze anchorage-independent growth, we examined the ability of hTERT-expressing normal and G6PD-deficient fibroblasts to form colonies in soft agar (Fig. 3B). Whereas the fibrosarcoma HT1080 cells displayed 60\% colony-forming efficiency, colony formation was not detected in hTERT-expressing normal or G6PDdeficient fibroblasts from six independent experiments with $5 \times 10^{3}$ cells plated in each experiment, indicating that these immortal cells do not acquire an anchorageindependent growth phenotype. 
A

$\begin{array}{llll}\mathrm{N} & \mathrm{P} & \mathrm{H} & \mathrm{V} 1 \mathrm{~V} 2 \mathrm{GV} 1 \mathrm{GV} 2\end{array}$

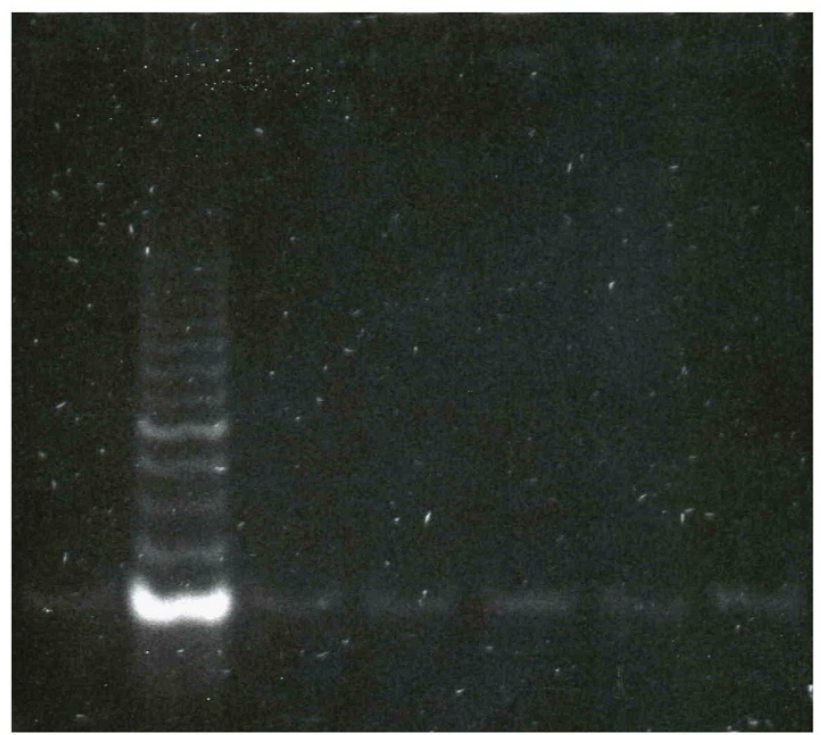

B

\section{$\begin{array}{lllll}\mathrm{N} & \mathrm{P} & \mathrm{H} & \mathrm{T} 5 & \mathrm{~T} 9 \mathrm{GT} 3 \mathrm{GT}\end{array}$}

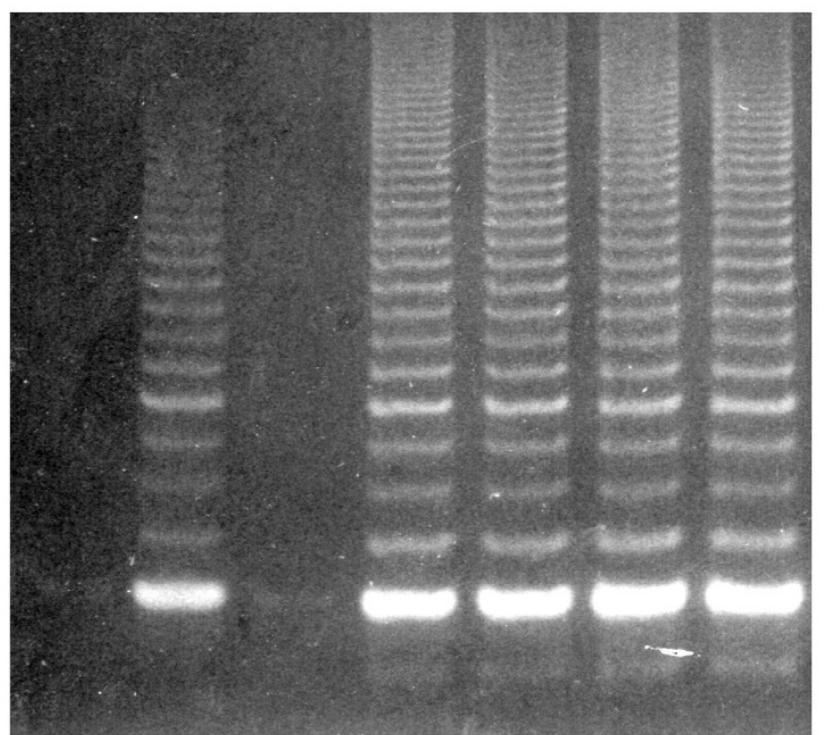

Figure I

Telomerase activity of hTERT-transfected normal and G6PD-deficient fibroblasts. Normal fibroblasts HFF3 and G6PD-deficient fibroblasts HFFI were infected with retroviral vector pBABE-Puro (Panel A) or pBABE-Puro-hTERT (Panel B). G4I8-resistant clones were obtained from HFF3 infected with vector alone (VI, V2) or with pBABE-Puro-hTERT (T5, T9), and from HFFI cells infected with vector alone (GVI, GV2) or with PBABE-Puro-hTERT (GT3, GT8). Telomerase activity in these G-4 18 resistant clones was assayed by TRAP as described in $M$ \& $M$. Lanes labeled with $N, P, H$ are negative control with no cell extract, positive control with cell extract from a telomerase-positive HT- 1080 cells, and heat-inactivated HT-I080 cell extract, respectively.

\section{Telomere length stabilizes after reaching a critical length} in hTERT-expressing G6PD-deficient fibroblasts

Expression of telomerase is thought to counteract telomere attrition and thus provide escape from replicative senescence. To determine whether the ectopic expression of hTERT stabilizes telomere length in G6PD-deficient fibroblasts, we analyzed TRF lengths. As shown in Figure $4 \mathrm{~A}$, telomere length continued to decrease in hTERTexpressing normal fibroblasts, T5 and T9, in early-passage cells, despite the fact that these cells express high levels of telomerase activity. After passage 36, the TRF length in T5 cells appeared to stabilize at approximately $3.3 \mathrm{~kb}$, whereas TRF length in T9 cells increased in later passages, increasing from $\sim 3.3 \mathrm{~kb}$ to $6.2-8.5 \mathrm{~kb}$. Both hTERTexpressing G6PD-deficient fibroblasts, GT3 and GT8, displayed a pattern of telomere length reduction and stabilization that was similar to that of normal T5 cells, with TRF decreasing in earlier-passage cells but then stabilizing at 3-3.7 kb after passage 36 (Fig. 4B).

\section{Resistance of hTERT-expressing G6PD-deficient fibroblasts to $\mathrm{H} 2 \mathrm{O} 2$-induced premature senescence}

To address the mechanism by which ectopic expression of hTERT enables G6PD-deficient cells to overcome premature senescence, we measured the ability of hTERTexpressing cells to cope with oxidative stress induced by treatment with exogenous $\mathrm{H}_{2} \mathrm{O}_{2}$. As shown in Figure $5 \mathrm{~A}$, under normal culture conditions there were very few cells among G6PD-deficient HFF1 fibroblasts (passage 22) and hTERT-expressing G6PD-deficient GT3 fibroblasts (passage 72 ) that were positive for SA- $\beta$-Gal staining (less than $5 \%$ ). Treatment with $\mathrm{H}_{2} \mathrm{O}_{2}$ increased the number of SA- $\beta$ Gal-positive cells in both the HFF1 and GT3 populations, indicating that $\mathrm{H}_{2} \mathrm{O}_{2}$ induces premature senescence in both cells. Interestingly, we noted that there is a greater increase of SA- $\beta$-Gal-positive cells in the $\mathrm{H}_{2} \mathrm{O}_{2}$-treated HFF1 cells ( $55 \pm 9 \%$ ) than in the $\mathrm{H}_{2} \mathrm{O}_{2}$-treated GT3 cells $(21 \pm 1.4 \%)$. To confirm the significance of this observation, we treated parental and hTERT-expressing fibroblasts 
A

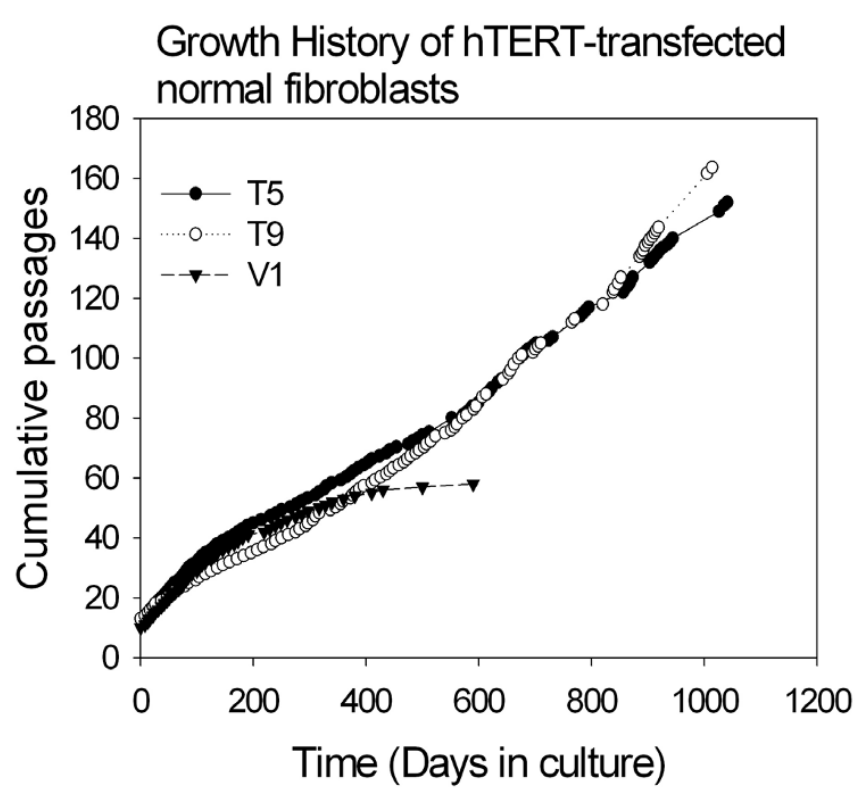

C
(T5)

B
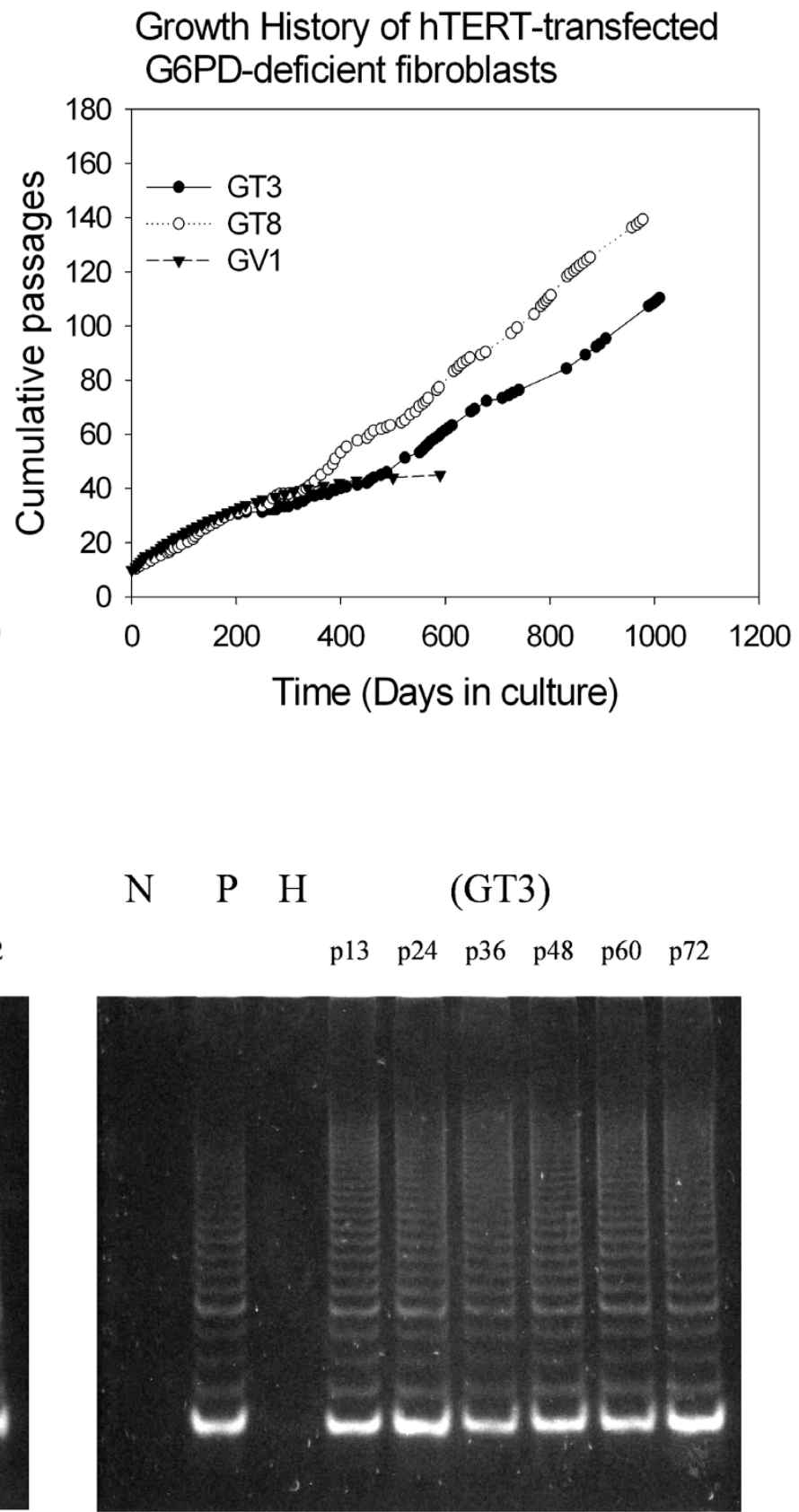

\section{Figure 2}

Proliferation capability of hTERT-transfected normal and G6PD-deficient fibroblasts. Normal fibroblasts HFF3 (Panel A) and G6PD-deficient fibroblasts HFFI (Panel B) were infected with retroviral vector pBABE-Puro or pBABE-PurohTERT, and G418-resistant clones were obtained as described in legend to Fig. I. These G4I8-resistant cells were cultivated by successive passages with I:8 spliting. The telomerase activity of hTERT-transfected T5 and GT3 cells at various passages ( $\mathrm{p} / 3$ to p72) was determined by TRAP and shown in Panel C. Lanes labeled with N, P, H in Panel C are negative control with no cell extract, positive control with cell extract from a telomerase-positive HT- 1080 cells, and heat-inactivated HT- 1080 cell extract, respectively. 


(1)

B

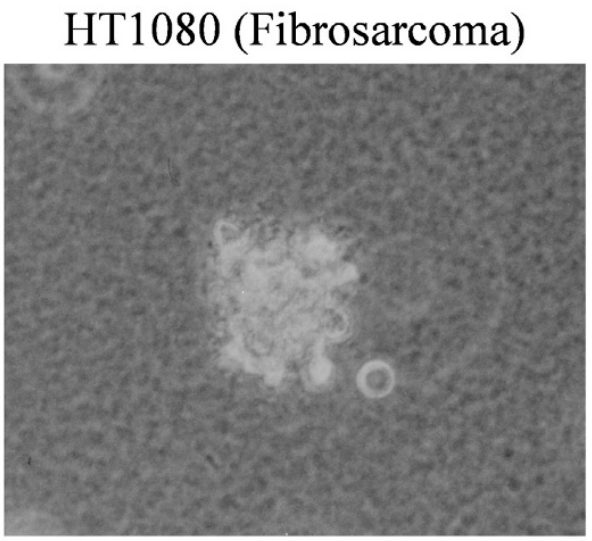

hTERT-expressing fibroblasts

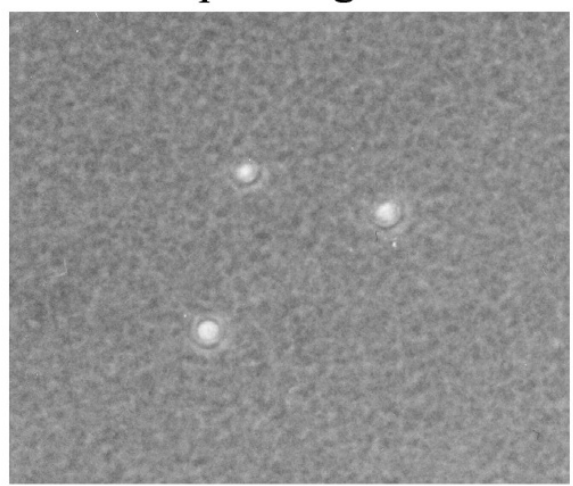

Figure 3

The karyotypes and anchorage-independent growth potential of hTERT-expressing normal and G6PD-deficient fibroblasts. The karyotypes of hTERT-expressing normal fibroblasts (T5) and G6PD-deficient fibroblasts (GT3) were determined as described in Materials and Methods; representative data are shown in panel A. Anchorage-independent growth was assayed by the ability to form colonies in soft agar. Representative results for hTERT-expressing G6PD-deficient fibroblasts are shown in panel B (right panel); no colonies formed and only single cells were detected. In HTI080 fibrosarcoma cell positive controls, colonies were detected (left panel). 
A

T5

S $\quad$ L P p13 p24 p36 p48 p60 p72

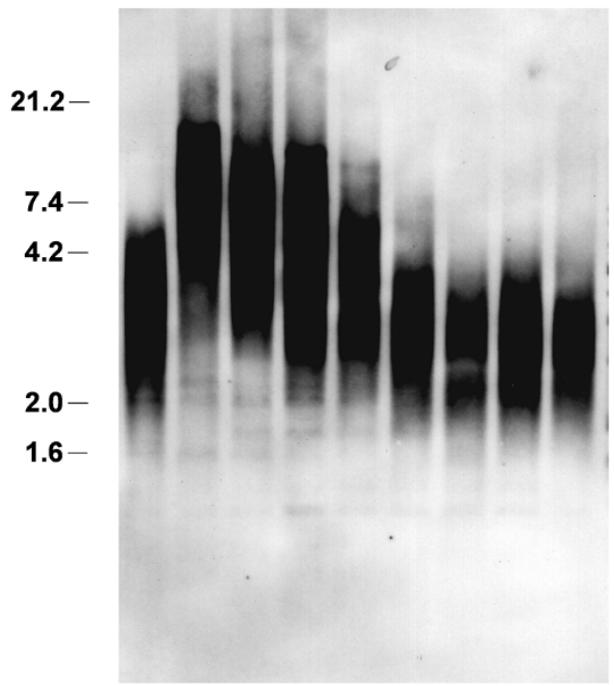

Mean TRF

length $(\mathrm{kb})$

B
T9

S L P p13 p24 p36 p48 p60 p72

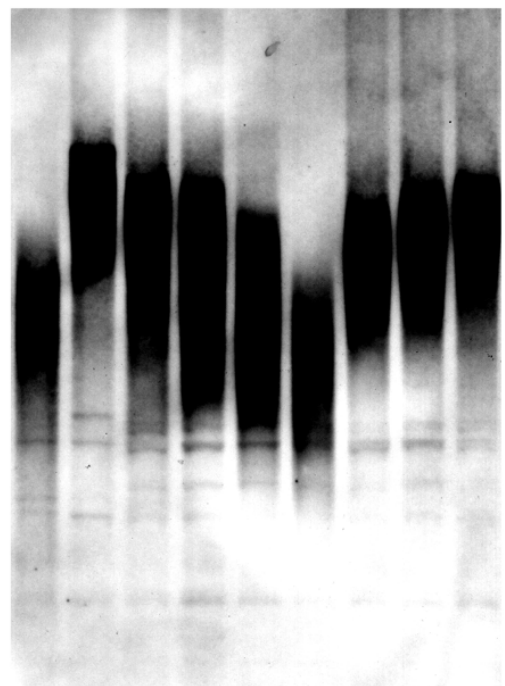

$\begin{array}{lllllllll}3.9 & 10.2 & 7.9 & 6.6 & 4.0 & 3.3 & 6.2 & 7.4 & 8.5\end{array}$

GT8

S L P p13 p24 p36 p48 p60 p72
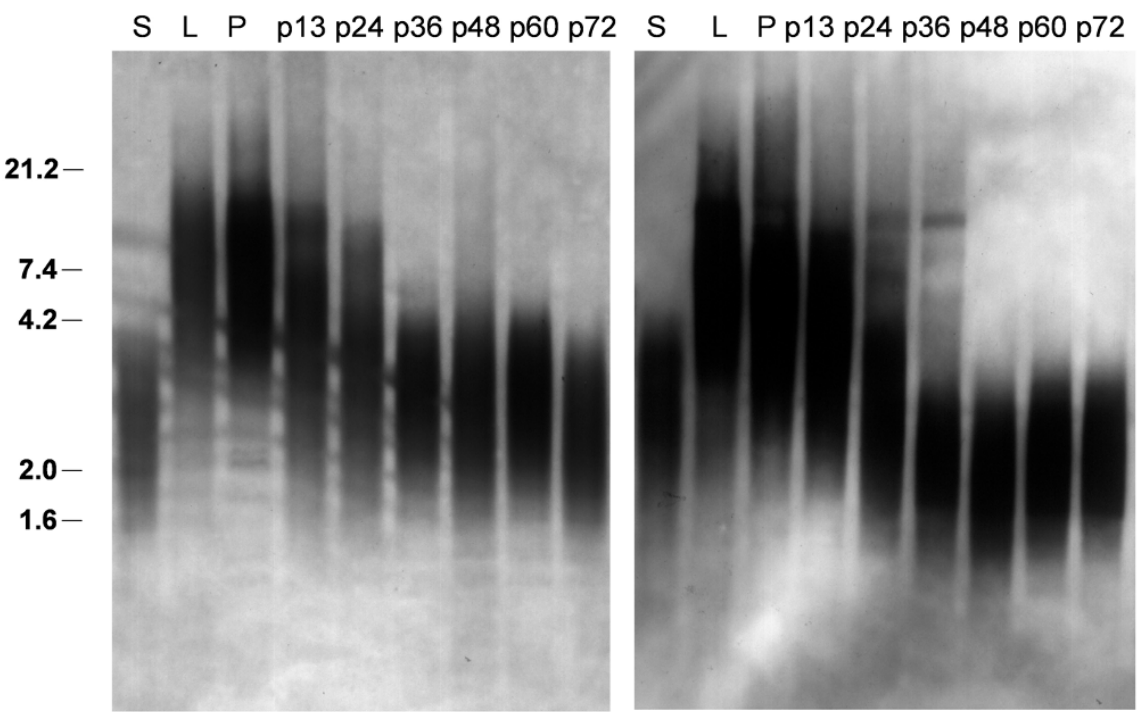

Mean TRF

length $(\mathrm{kb})$

$\begin{array}{lllllllll}3.9 & 10.2 & 8.2 & 7.5 & 5.5 & 3.7 & 3.5 & 3.7 & 3.0\end{array}$

$\begin{array}{lllllllll}3.9 & 10.2 & 8.3 & 5.5 & 3.7 & 3.0 & 2.8 & 3.0 & 3.1\end{array}$

\section{Figure 4}

Telomere lengths of hTERT-expressing normal and G6PD-deficient fibroblasts. Cells were cultivated successively by I:8 spliting in each passage. The telomere lengths of hTERT-expressing normal fibroblasts (Panel A) and G6PD-deficient fibroblasts (Panel $B$ ) at different passages were determined as described in $M$ \& $M$. Lanes $S$ and $L$ are controls supplied with the assay kit for DNAs having short or long TRF lengths, respectively. Lane P is the DNA from the parental cells before transfection. The mean telomere restriction fragment (TRF) lengths in kilobases (kb) are indicated below each lane. Molecular weight (M.W.) markers ranging from 1.6 to $21.2 \mathrm{~kb}$ are marked at the left. 
A

HFF1

GT3
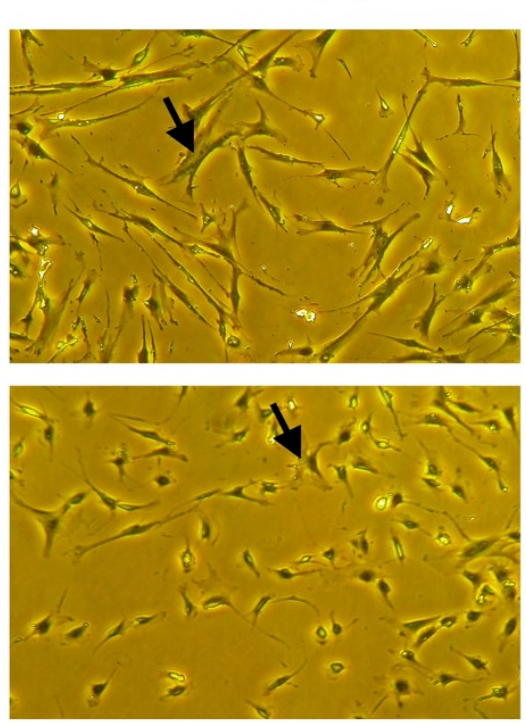

with $\mathrm{H}_{2} \mathrm{O}_{2}$
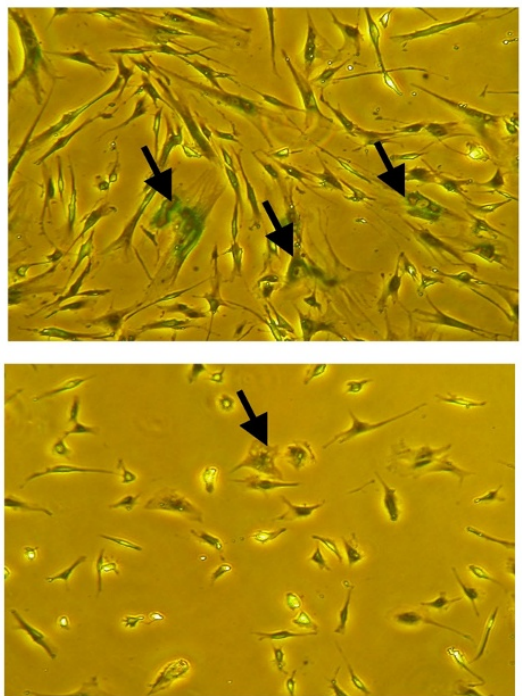

\section{B}

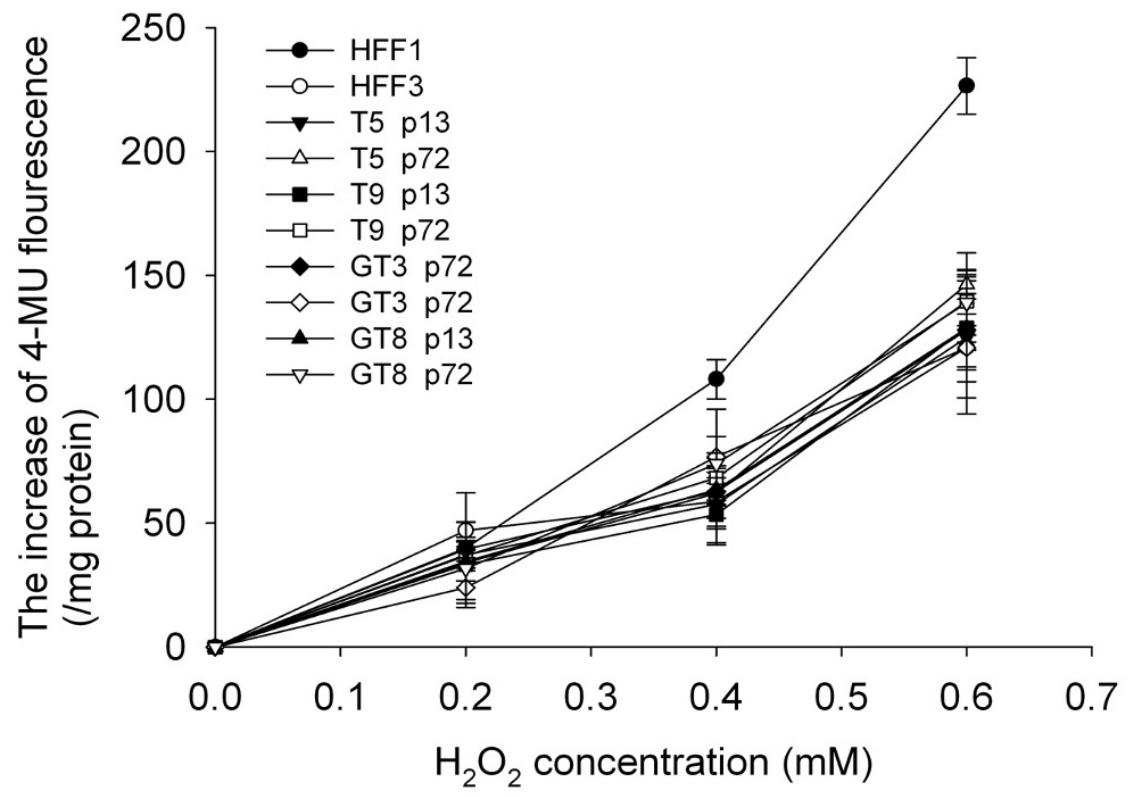

Figure 5

$\mathbf{H}_{2} \mathrm{O}_{2}$-induced senescence in G6PD-deficient fibroblasts. A. Cells were treated with $350 \mu \mathrm{M} \mathrm{H} \mathrm{O}_{2}$ for I.5 h and then cultured for another $72 \mathrm{~h}$ before staining for senescence-associated $\beta$-galactosidase (SA- $\beta$-Gal) activity. Representative results for HFFI and GT3 cells with or without $\mathrm{H}_{2} \mathrm{O}_{2}$ treatment are shown in the right and left panels, respectively. Examples of cells that are positive for SA- $\beta$-Gal staining are indicated by arrow. In the quantification, any cell that has detectable green staining was scored as positive for SA- $\beta-$ Gal. B. Cells were treated with different concentrations of $\mathrm{H}_{2} \mathrm{O}_{2}$ for I.5 h and then cultured for another $72 \mathrm{~h}$. Quantification of premature senescence was determined by the rate of conversion of 4-methylumbelliferyl$\beta$-D-galactopyranoside (MUG) to fluorescent product 4-methylumbelliferone (4-MU) as described in M \& M. Both the early passage ( $\mathrm{pl3}$ ) and late passage (p72) cells of T5, T9, GT3 and GT8 were included in this study. Data are the means \pm SD from 4 independent experiments. 
from both normal and G6PG-deficient patients with different concentrations of $\mathrm{H}_{2} \mathrm{O}_{2}$ and quantified the extent of $\mathrm{H}_{2} \mathrm{O}_{2}$-induced premature senescence. As shown in Figure $5 \mathrm{~B}$, the levels of $\mathrm{H}_{2} \mathrm{O}_{2}$-induced premature senescence in the early passage (p13) and late passage (p72) cells of T5, T9, GT3 and GT8 were similar to HFF3, but were significantly greater in HFF1 cells. These results indicate that ectopic expression of hTERT in G6PD-deficient cells renders the cells more resistant to $\mathrm{H}_{2} \mathrm{O}_{2}$-induced premature senescence.

\section{Discussion}

The accelerated cellular senescence characteristic of G6PD-deficient fibroblasts would seem to represent a clear case of a senescence mechanism based on accumulated oxidative DNA damage rather than one involving accelerated telomere attrition [26]. This mechanistic transparency makes these cells an ideal system for addressing the relative role of oxidative stress and telomere attrition in cellular senescence. Somewhat surprisingly, we found that ectopic expression of hTERT prevented the accelerated senescence of G6PD-deficient cells and led to their immortalization (Fig. 2). The growth rate of hTERT-expressing G6PD-deficient fibroblasts, however, remained slower than that of hTERT-expressing normal fibroblasts (Fig. 2A and 2B), as noted previously (25). This finding suggests that hTERT overexpression may attenuate senescence induction by oxidative stress, but does not suppress the growth defect caused by G6PDdeficiency. To test this hypothesis, we measured the ability of hTERT-expressing G6PD-deficient cells to cope with $\mathrm{H}_{2} \mathrm{O}_{2}$-induced oxidative stress. Similar to results reported by others [31], we found no difference in stress-induced premature senescence (SIPS) between normal and hTERTexpressing normal fibroblasts (Fig. 5). However, hTERTexpressing G6PD-deficient cells became more resistant to $\mathrm{H}_{2} \mathrm{O}_{2}$-induced premature senescence (Fig. 5), indicating that the increased sensitivity to oxidative stress in G6PDdeficient cells is prevented by the expression of hTERT.

Ectopic expression of hTERT has also been shown previously to immortalize fibroblasts derived from individuals with Ataxia telangiectasia (A-T), Nijimegen breakage syndrome (NBS), Hutchinson-Gilford progeria syndrome (HGPS), and Werner Syndrome (WS) [32-36]. Although the genetic defects in A-T, NBS, HGPS, WS, and G6PDdeficiency patients are very different, fibroblasts derived from these individuals have one common phenotype: they all undergo accelerated senescence in vitro $[25,34,36,37]$. The premature senescence of mitotic cells derived from A-T, HGPS, and NBS patients has been correlated with an increased rate of telomere loss [31,34,38], whereas the mechanism responsible for the premature senescence of WS and G6PD-deficient fibroblasts appears to be different and has been postulated to reflect the accu- mulation of DNA damage [26,38]. The fact that ectopic expression of hTERT immortalizes fibroblasts derived from individuals with any of these different defects indicates that telomerase may attenuate senescence induction triggered by either telomere attrition or genome-wide DNA damage. Ectopic expression of hTERT has also been shown to increase radioresistance of adult human mesenchymal stem cells [39], to circumvent hyperglycemiainduced premature senescence [40], and to prevent apoptosis induced by tumor necrosis factor [41]. These observations suggest that expression of hTERT not only activates telomere maintenance but may also affect signaling that protects cells from oxidative stress and other stimuli. Indeed, increasing evidence is emerging to implicate that hTERT has functions beyond telomere maintenance [42].

hTERT-immortalization of cells is generally attributed to the activation of telomerase activity and the subsequent counteraction of telomere attrition. Surprisingly, we observed that telomere lengths continued to decrease in earlier-passage cells from both hTERT-expressing normal and G6PD-deficient fibroblasts, despite the fact that these cells expressed high levels of telomerase activity (Fig. 1). In fact, we observed that TRF lengths from one hTERTexpressing normal cell line (T5) and two hTERT-expressing G6PD-deficient cell lines (GT3 and GT8) were shortened to $\sim 3-3.7 \mathrm{~kb}$ before stabilization (Fig. 4). The parental fibroblasts used for the derivation of these hTERT-expressing cells undergo senescence when TRF lengths decrease to approximately 5-6 kb [25], suggesting that dysfunctional telomeres may already have formed when the TRF length was reduced to 5-6 kb in normal fibroblasts. However, senescence was not induced in these hTERT-expressing cells even when the TRF lengths were reduced to less than $5 \mathrm{~kb}$, suggesting that hTERT, in addition to serving as a subunit for telomerase, acts by some other mechanism to prevent senescence induction. Shortening of telomere lengths in the presence of telomerase activation has also been observed by others [28,43], and a protective role for hTERT in telomere capping has been suggested $[28,44]$. In addition, hTERT has been found to associate with human telomeres, and ectopic expression of hTERT causes transcriptional alterations in a subset of genes; this may lead to increased genomic stability and enhanced DNA repair activity [45]. At this time, the molecular details of hTERT involvement in senescence induction remain obscure.

It is currently not known why activation of telomerase does not result in an immediate stabilization of telomere lengths. Presumably, telomere length is influenced not only by telomerase levels but also depends on a control pathway that acts in cis at each individual telomere [46]. Several telomere-binding proteins, such as TRF1, TRF2, 
and Pot1, are known to participate in telomere-length regulation and chromosome-end protection [46]. It is likely that some of these factors prevent telomerase from functioning at the telomere until telomeres are shortened to a critical length. Our finding that the lengths of telomeres in hTERT-expressing cells were reduced to approximately 3$3.7 \mathrm{~kb}$ before stabilization (Fig. 4) provides support for this notion.

In conclusion, we have shown that ectopic expression of hTERT immortalizes fibroblasts derived from normal and G6PD-deficient patients. The accelerated cellular senescence observed in G6PD-deficient cells has been shown to be attributable to increased accumulation of oxidative DNA damage [26]. As this oxidant-induced senescence was overridden by the ectopic expression of hTERT, we suggest that hTERT, in addition to providing a subunit for telomerase, may also function in regulating senescence induction.

\section{Competing interests}

The authors declare that they have no competing interests.

\section{Authors' contributions}

$\mathrm{MC}$ and $\mathrm{HH}$ participated in the preparation of retroviral particles and isolation of hTERT-expressing clones, YW carried out the rest of research, DTC and TVW conceived of the study and design research, YW and TVW wrote the paper. All authors read and approved the final manuscript.

\section{Acknowledgements}

This work was supported by grants from Chang Gung University (CMRPI6023I) and the National Science Council of Taiwan (NSC94-2320BI82-04I) to DTYC; and from Chang Gung University (CMRPDI400I2) and the National Science Council of Taiwan (NSC95-23II-BI82-00I) to TCVW. This work was also supported by a grant from the Ministry of Education (EMRPDI7058I) to DTYC and TCVW.

\section{References}

I. Hayflick L, Moorhead PS: The serial cultivation of human diploid cell strains. Exp Cell Res I96I, 25:585-62I.

2. Campisi J, Kim SH, Lim CS, Rubio M: Cellular senescence, cancer and aging: the telomere connection. Exp Gerontol 200I, 36:607-618.

3. Ben-Porath I, Weinberg RA: The signals and pathways activating cellular senescence. Int J Biochem Cell Biol 2005, 37:96I-976.

4. Harley CB, Vaziri H, Counter CM, Allsopp RC: The telomere hypothesis of cellular aging. Exp Gerontol 1992, 27:375-382.

5. Harley CB, Kim NW, Prowse KR, Weinrich SL, Hirsch KS, West MD, Bacchetti S, Hirte HW, Counter CM, Greider CW, et al: Telomerase, cell immortality, and cancer. Cold Spring Harb Symp Quant Biol 1994, 59:307-3।5.

6. Harman D: Aging: a theory based on free radical and radiation chemistry. J Gerontol 1956, I I:298-300.

7. Sohal RS, Weindruch R: Oxidative stress, caloric restriction, and aging. Science 1996, 273:59-63.

8. Harley $C B$, Futcher $A B$, Greider $C W$ : Telomeres shorten during ageing of human fibroblasts. Nature 1990, 345:458-460.

9. Lingner J, Cooper JP, Cech TR: Telomerase and DNA end replication: no longer a lagging strand problem? Science 1995, 269:1533-1534.
10. Greider $\mathrm{CW}$, Blackburn $\mathrm{EH}$ : Telomeres, telomerase and cancer. Sci Am 1996, 274:92-97.

II. Stewart SA, Weinberg RA: Telomerase and human tumorigenesis. Semin Cancer Biol 2000, 10:399-406.

12. Kim NW, Piatyszek MA, Prowse KR, Harley CB, West MD, Ho PL, Coviello GM, Wright WE, Weinrich SL, Shay JW: Specific association of human telomerase activity with immortal cells and cancer. Science 1994, 266:201I-2015.

13. Shay JW, Bacchetti S: A survey of telomerase activity in human cancer. Eur J Cancer 1997, 33:787-79I.

14. Bodnar AG, Ouellette M, Frolkis M, Holt SE, Chiu CP, Morin GB, Harley CB, Shay JW, Lichtsteiner S, Wright WE: Extension of life-span by introduction of telomerase into normal human cells. Science 1998, 279:349-352.

15. Vaziri H, Benchimol S: Reconstitution of telomerase activity in normal human cells leads to elongation of telomeres and extended replicative life span. Curr Biol 1998, 8:279-282.

16. Nakayama J, Tahara H, Tahara E, Saito M, Ito K, Nakamura H, Nakanishi T, Tahara E, Ide T, Ishikawa F: Telomerase activation by hTRT in human normal fibroblasts and hepatocellular carcinomas. Nat Genet 1998, 18:65-68.

17. Toussaint $O$, Houbion A, Remacle J: Aging as a multi-step process characterized by a lowering of entropy production leading the cell to a sequence of defined stages. II. Testing some predictions on aging human fibroblasts in culture. Mech Ageing Dev 1992, 65:65-83.

18. Dumont P, Burton M, Chen QM, Gonos ES, Frippiat C, Mazarati JB, Eliaers F, Remacle J, Toussaint $O$ : Induction of replicative senescence biomarkers by sublethal oxidative stresses in normal human fibroblast. Free Radic Biol Med 2000, 28:36I-373.

19. Chen Q, Ames BN: Senescence-like growth arrest induced by hydrogen peroxide in human diploid fibroblast F65 cells. Proc Natl Acad Sci USA 1994, 9 1:4130-4I34.

20. Honda $S$, Matsuo M: Shortening of the in vitro lifespan of human diploid fibroblasts exposed to hyperbaric oxygen. Exp Gerontol 1983, 18:339-345.

2I. von Zglinicki T, Saretzki G, Docke W, Lotze C: Mild hyperoxia shortens telomeres and inhibits proliferation of fibroblasts: a model for senescence? Exp Cell Res 1995, 220:186-193.

22. Chen Q, Fischer A, Reagan JD, Yan LJ, Ames BN: Oxidative DNA damage and senescence of human diploid fibroblast cells. Proc Natl Acad Sci USA 1995, 92:4337-434I.

23. Gaubatz S, Lees JA, Lindeman GJ, Livingston DM: E2F4 is exported from the nucleus in a CRMI-dependent manner. Mol Cell Biol 2001, 2 I: I 384-I392.

24. Ho HY, Cheng ML, Cheng PF, Chiu DT: Low oxygen tension alleviates oxidative damage and delays cellular senescence in G6PD-deficient cells. Free Radic Res 2007, 41:57|-579.

25. Ho HY, Cheng ML, Lu FJ, Chou YH, Stern A, Liang CM, Chiu DT: Enhanced oxidative stress and accelerated cellular senescence in glucose-6-phosphate dehydrogenase (G6PD)-deficient human fibroblasts. Free Radic Biol Med 2000, 29:156-169.

26. Cheng ML, Ho HY, Wu YH, Chiu DT: Glucose-6-phosphate dehydrogenase-deficient cells show an increased propensity for oxidant-induced senescence. Free Radic Biol Med 2004, 36:580-591.

27. Yu CC, Lo SC, Wang TC: Telomerase is regulated by protein kinase C-zeta in human nasopharyngeal cancer cells. Biochem J 200I, 355:459-464

28. Zhu J, Wang H, Bishop JM, Blackburn EH: Telomerase extends the lifespan of virus-transformed human cells without net telomere lengthening. Proc Natl Acad Sci USA 1999, 96:3723-3728.

29. Sheng WY, Chien YL, Wang TC: The dual role of protein kinase $C$ in the regulation of telomerase activity in human lymphocytes. FEBS Lett 2003, 540:91-95.

30. Gary RK, Kindell SM: Quantitative assay of senescence-associated beta-galactosidase activity in mammalian cell extracts. Anal Biochem 2005, 343:329-334.

31. Naka K, Tachibana A, lkeda K, Motoyama N: Stress-induced premature senescence in hTERT-expressing ataxia telangiectasia fibroblasts. J Biol Chem 2004, 279:2030-2037.

32. Wood LD, Halvorsen TL, Dhar S, Baur JA, Pandita RK, Wright WE, Hande MP, Calaf G, Hei TK, Levine F, et al:: Characterization of ataxia telangiectasia fibroblasts with extended life-span through telomerase expression. Oncogene 200I, 20:278-288. 
33. Nakamura $H$, Fukami $H$, Hayashi $Y$, Kiyono $T$, Nakatsugawa $S$, Hamaguchi M, Ishizaki K: Establishment of immortal normal and ataxia telangiectasia fibroblast cell lines by introduction of the hTERT gene. J Radiat Res (Tokyo) 2002, 43: I67-I74.

34. Ranganathan V, Heine WF, Ciccone DN, Rudolph KL, Wu X, Chang $\mathrm{S}$, Hai H, Ahearn IM, Livingston DM, Resnick I, Rosen Fred, Seemanova E, Jarolim P, DePinho RA, Weaver DT: Rescue of a telomere length defect of Nijmegen breakage syndrome cells requires NBS and telomerase catalytic subunit. Curr Biol 200I, I I:962-6.

35. Wyllie FS, Jones CJ, Skinner JW, Haughton MF, Wallis C, WynfordThomas D, Faragher RG, Kipling D: Telomerase prevents the accelerated cell ageing of Werner syndrome fibroblasts. Nat Genet 2000, 24:16-17.

36. Ouellette MM, McDaniel LD, Wright WE, Shay JW, Schultz RA: The establishment of telomerase-immortalized cell lines representing human chromosome instability syndromes. Hum Mol Genet 2000, 9:403-4II.

37. Faragher RG, Kill IR, Hunter JA, Pope FM, Tannock C, Shall S: The gene responsible for Werner syndrome may be a cell division "counting" gene. Proc Natl Acad Sci USA 1993, 90:12030-12034.

38. Allsopp RC, Vaziri H, Patterson C, Goldstein S, Younglai EV, Futcher $A B$, Greider $C W$, Harley $C B$ : Telomere length predicts replicative capacity of human fibroblasts. Proc Natl Acad Sci USA 1992, 89:10114-10118.

39. Serakinci N, Christensen R, Graakjaer J, Cairney CJ, Keith WN, Alsner J, Saretzki G, Kolvraa S: Ectopically hTERT expressing adult human mesenchymal stem cells are less radiosensitive than their telomerase negative counterpart. Exp Cell Res 2007, 313:1056-1067.

40. Blazer S, Khankin E, Segev Y, Ofir R, Yalon-Hacohen M, Kra-Oz Z Gottfried Y, Larisch S, Skorecki KL: High glucose-induced replicative senescence: point of no return and effect of telomerase. Biochem Biophys Res Commun 2002, 296:93-I0I.

41. Dudognon C, Pendino F, Hillion J, Saumet A, Lanotte M, Segal-Bendirdjian E: Death receptor signaling regulatory function for telomerase: hTERT abolishes TRAIL-induced apoptosis, independently of telomere maintenance. Oncogene 2004, 23:7469-7474.

42. Cong Y, Shay JW: Actions of human telomerase beyond telomeres. Cell Res 2008, 18:725-732.

43. Yang J, Chang E, Cherry AM, Bangs CD, Oei Y, Bodnar A, Bronstein $A$, Chiu CP, Herron GS: Human endothelial cell life extension by telomerase expression. J Biol Chem 1999, 274:26|4|-26|48.

44. Chan SW, Blackburn EH: Telomerase and ATM/Tellp protect telomeres from nonhomologous end joining. Mol Cell 2003, I I:1379-1387.

45. Sharma GG, Gupta A, Wang H, Scherthan H, Dhar S, Gandhi V, lliakis G, Shay JW, Young CS, Pandita TK: hTERT associates with human telomeres and enhances genomic stability and DNA repair. Oncogene 2003, 22:131-146.

46. Smogorzewska A, de Lange T: Regulation of telomerase by telomeric proteins. Annu Rev Biochem 2004, 73:177-208.
Publish with Biomed Central and every scientist can read your work free of charge

"BioMed Central will be the most significant development for disseminating the results of biomedical research in our lifetime. "

Sir Paul Nurse, Cancer Research UK

Your research papers will be:

- available free of charge to the entire biomedical community

- peer reviewed and published immediately upon acceptance

- cited in PubMed and archived on PubMed Central

- yours - you keep the copyright

Submit your manuscript here:

http://www.biomedcentral.com/info/publishing_adv.asp
BioMedcentral 